\title{
Application of various PID Controller Tuning Techniques for a Temperature System
}

\author{
V. Selvi Sowmya \\ UG student, \\ Department of ICE \\ Saranathan College \\ of Engineering,
}

\author{
S. Priya dharsini \\ UG student, \\ Department of ICE \\ Saranathan College \\ of Engineering,
}

\author{
R.Priya Dharshini \\ UG student, \\ Department of ICE \\ Saranathan College \\ of Engineering,
}

\author{
P. Aravind \\ Assistant Professor, \\ Department of ICE \\ Saranathan College \\ of Engineering,
}

\begin{abstract}
Control of temperature level in the process tank is vital in process industries. A proportional-integral-derivative controller (PID controller) is a control loop feedback mechanism (controller) widely used in industrial control systems.PID control is a control strategy that has been successfully used over many years. This algorithm involves three separate constant parameters. And it is otherwise called as three term controller. Where, $\mathrm{P}$ depends on the present error, I on the accumulation of past errors, and D is a prediction of future errors, based on current rate of change. It is highly used in chemical industries because of their success rate in practical applications, robustness and simplicity The PID temperature control algorithm is used for the control of almost all loops in the process industries, and is also the basis for many advanced control algorithms and strategies. A PID temperature controller works by measuring the current temperature to generate the error signal and altering the output to bring it closer to the target. The main alternative for temperature PID controller is ON/OFF controller which works like a thermostat. To determine the appropriate controller parameters settings, a conventional PID control tuning techniques and model based PID were characterized and their results to be obtained are simulated. With the yield of time domain and error criterion analysis, the most suitable controller for temperature controlled process is obtained. The best among the tuned controlled technique is pointed out as a good result of minimum rise time, setting time and overshoot.
\end{abstract}

\section{General Terms}

Process Control, Control System.

\section{Keywords}

PID controller, Temperature Control, CHR method.

\section{INTRODUCTION}

In 1930s Proportional - Integral - Derivative (PID) controller came to exist. Because of it generic and efficient output for real world control problems; it is being used even today. Hence it has been widely accepted in major process industries. It makes things easier for the operator who has to look into control of the system. Different tuning methods are compared in this study. To achieve optimum performance following are essential,

1. Dynamic model of the system,

2. Desired performance of closed loop system on the basis of known physical parameters,

\section{Adopting controller strategies for desired performance}

4. Implementation of the controller using suitable platform,

5. Validation of controller performance (1)
The PID controller is very popularly used in the feedback network. It has good clarity and its easy to implement. A PID controller helps to bring down the difference between the process variable and the set point by outputting the response with the desired value. PID controller has zero steady state error, fast response, short rise time, no oscillations and higher stability. PID controllers are preferred over PI controllers because they reduce the overshoot and it also holds added advantage of employability for higher order systems. A PID controller propels a control signal that has a component proportional to the error of a system, accumulation of the error over time and the rate of change of the error with respect to time.

Mostly every system will have multiple and contradictory objectives to be achieved. For designing a controller by satisfying all the requirements we need algorithms so as to tackle the problems that may arise. The conventional tuning methods which works based on fixed parameters will result in lesser performance when system necessitates controller. We will discuss about the four tuning techniques-Ziegler-Nichols (ZN), Ziegler Chien Hrones Reswich (C-H-R), Tyreuslubeyn(T-L) for designing the PID controllers. From the above specified tuning methods, the proportional band, integral time and derivative time can be calculated. By using those values one can determine the Proportional constant $(\mathrm{Kc})$, Integral constant $(\mathrm{Ki})$ and Derivative constant $(\mathrm{Kd}) . \mathrm{It}$ also includes the PID values $[\mathrm{Kc}, \mathrm{Ki}, \mathrm{Kd}]$ of the four tuning methods and the Tuning method of Minimum Error Integral Criteria for determining the error values of ITAE, ISE, IAE, MSE. Temperature control is a process in which change of temperature of a space (and objects collectively there within) is measured or otherwise detected, and the passage of heat energy into or out of the space is adjusted to achieve a desired average temperature.

\section{SYSTEM IDENTIFICATION \\ 2.1. Mathematical Modeling}

To analyze the behavior of a process, a mathematical representation of the physical and chemical phenomenon taking place in it is essential and this representation constitutes the mathematical model.

\subsection{Experimental Setup}

The experimental set up shown in Figure 1 consists of water supply tank, pump, Plunger pump, temperature transmitter, pressure transmitter, Process tanks with differential pressure transmitters, rotameter, pneumatic control valve, I/P converter, Pressure gauges(16). The pneumatic control valve is air to close, adjusts the flow of the water pumped to the cylindrical tank from the water reservoir. The temperature of the water in the tank is measured by means of the temperature transmitter and is transmitted in the form of (4-20) $\mathrm{mA}$ to the 
interfacing ADAM's module to the Personal Computer (PC). In this process, either RTD (Resistance Temperature Detector) or Thermocouple can be used to measure the temperature level in the process. A step test is performed on temperature process station and process is identified as first order plus dead time model defined by terms process gain $(\mathrm{K})-5$, time $\operatorname{constant}(\tau)-2$, dead time (Td)- 4 .

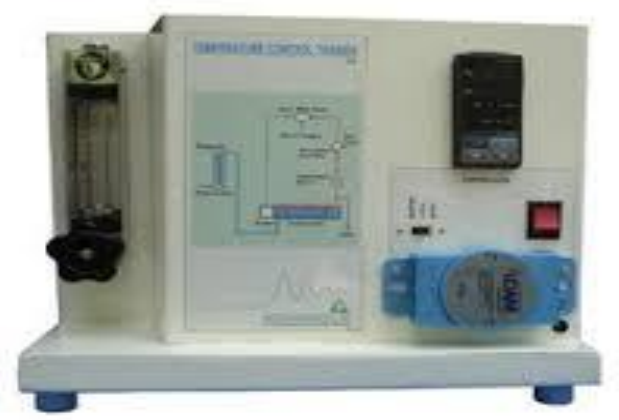

Fig. 1Experimental Setup of Temperature Process

\section{PID TUNING METHODS}

The various tuning methods used here are
1. Zieger-Nichols (Z-N) method
2. Tyreus-Lubeyn method(T-L) method
3. Chien-hrones-Reswick (C-H-R) method

\subsection{Zieger-Nichols Method}

The Ziegler-Nichols tuning method is a heuristic method of tuning a PID controller. It was developed by John G. Ziegler and Nathaniel B. Nichols. It is performed by setting the $I$ (integral) and $D$ (derivative) gains to zero.(4) The "P" (proportional) gain, $\mathrm{Kp}$ is then increased (from zero) until it reaches the ultimate gain, ku at which the output of the control loop oscillates with constant amplitude. $\mathrm{Ku}$ and the oscillation period Tu are used to set the $\mathrm{P}, \mathrm{I}$, and $\mathrm{D}$ gains depending on the type of controller used (6).

The Ziegler-Nichols method attempts to produce good values for the three PID gain parameters:

1. $K p$ - the controller path gain

2. $T i$ - the controller's integrator time constant

3. $T d$ - the controller's derivative time constant

The proportional, integral and derivative values of ZieglerNichols method are $\mathrm{Kp}=0.238, \mathrm{Ki}=0.065, \mathrm{Kd}=0.2168$. The response for this method has a rise time 5.66 second and it attains the overshoot of $1.17 \%$ at 7.58 second and it settles at 22 second.

\subsection{Tyreus-Lubeyn Method}

This method (18) is also called as online tuning method. They had developed tuning method in closed-loop mode. This closed-loop tuning method overcomes the shortcoming of the well-known Ziegler-Nichols continuous cycling method and gives consistently better performance and robustness for broad class of processes. The PI/PID controller design method has been discussed extensively in the literature and it shows that most of the tuning method is based on the two steps procedure which is very easy to calculate the parameters.
The proportional, integral and derivative values of tyreuslubeyn method are $\mathrm{Kp}=0.124, \mathrm{Ki}=0.00773, \mathrm{Kd}=0.143$. The response for this method has a rise time 235 second and it settles at 235 second (11).

\subsection{Chien-Hrones-Reswick Method:}

The Chien-Hrones-Reswick auto tuning method focuses on setpoint response and disturbance response. This method provides formulas for $0 \%$ and $20 \%$ overshoot (18).

Table 1: Controller Tuning Parameters

\begin{tabular}{|l|c|c|c|}
\hline Controller & $\mathbf{K}_{\mathbf{c}}$ & $\mathbf{T}_{\mathbf{i}}$ & \multicolumn{1}{c|}{$\mathbf{T}_{\mathbf{d}}$} \\
\hline $\mathrm{P}$ & $0.3 T_{P} / \tau$ & - & - \\
\hline $\mathrm{PI}$ & $0.6 T_{P} / \tau$ & $4 \tau$ & - \\
\hline $\mathrm{PID}$ & $0.95 T_{P} / \tau$ & $2.4 \tau$ & $0.42 \tau$ \\
\hline
\end{tabular}

where $T_{P}$ is the time constant.

The proportional, integral and derivative values ChienHrones-Reswick of are $\mathrm{Kp}=0.12, \mathrm{Ki}=0.015, \mathrm{Kd}=0.20$. The response for this method has a rise time 98 second and it settles at 98 second.

\section{ERROR CRITERIA}

\subsection{Integral of the Absolute Value of the Error (IAE):}

Integral absolute error is a process which fits a sample to a certain outcome to show the closeness of the fitness measure of the results to the targeted value (18). Its response is slower than ISE but with less sustained oscillation.

$$
\mathrm{I}_{\mathrm{IAE}}=\int_{0}^{\mathrm{T}}|\mathrm{e}(\mathrm{t})| \mathrm{dt}
$$

\subsection{Integral of the Square Value of the Error (ISE):}

Integral square error is error from an output, squared and added integrated over time in continuous systems is used to measure system performance in applications of optimal control and estimation(4). It eliminates the large errors quickly. It produce fast responses, but with considerable, low amplitude, oscillation.

$$
I_{I S E}=\int_{0}^{T}\left|e^{2}(t)\right| d t
$$

\subsection{Integral of the Time Weighted Absolute Value of the Error (ITAE):}

In ITAE absolute error multiplied by time is integrated over time. It is to weight errors which exist after a long time much more heavily than those at the start of the response. Systems tuned by ITAE will settle much more quickly when compared to other two tuning methods (15). It produces system with sluggish initial response which avoids sustained oscillation.

$$
\mathrm{I}_{\text {ITAE }}=\int_{0}^{\mathrm{T}} \mathrm{t}|\mathrm{e}(\mathrm{t})| \mathrm{dt}
$$




\subsection{Mean Square Error (MSE):}

Mean Square Error is simple to use, natural to define energy of a signal, which possesses symmetry and differentiability (4). It is widely used in signal processing.

Table 2. PID Tuning Values

\begin{tabular}{|l|l|l|l|}
\hline Tuning Methods & Kp & Ki & Kd \\
\hline Ziegler Nichol's & 0.238 & 0.065 & 0.2168 \\
\hline Tyreus Luyben & 0.124 & 0.00773 & 0.143 \\
\hline CHR & 0.12 & 0.015 & 0.20 \\
\hline
\end{tabular}

\section{RESULT AND COMPARSION}

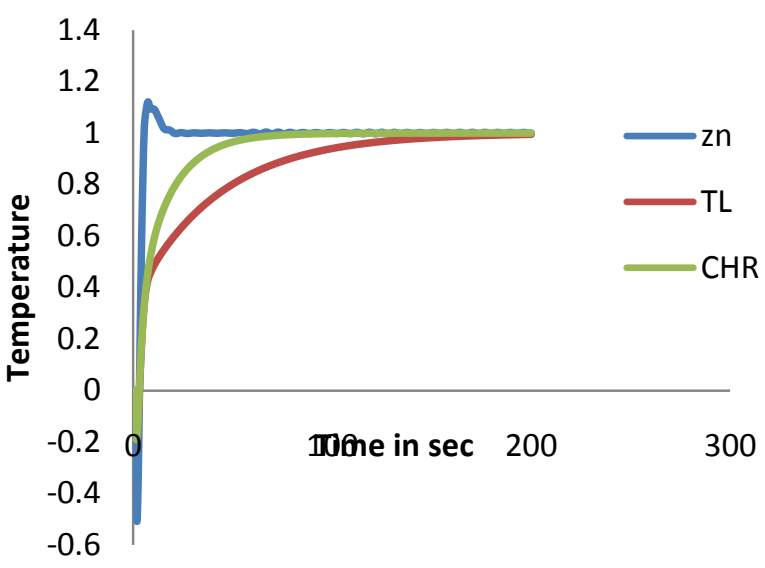

Figure 2: Comparison of Simulated Response for different control techniques

The Comparisons of different PID controllers tuning methods are below,

Table 3. Time Domain Specification:

\begin{tabular}{|l|l|l|l|l|}
\hline $\begin{array}{l}\text { Tuning } \\
\text { Methods }\end{array}$ & $\begin{array}{l}\text { Peak } \\
\text { Time }\end{array}$ & $\begin{array}{l}\text { Rise } \\
\text { Time }\end{array}$ & $\begin{array}{l}\text { Peak } \\
\text { Overshoot }\end{array}$ & $\begin{array}{l}\text { Settling } \\
\text { Time }\end{array}$ \\
\hline $\begin{array}{l}\text { Ziegler } \\
\text { Nichol's }\end{array}$ & 7.58 & 5.66 & 1.117 & 22 \\
\hline $\begin{array}{l}\text { Tyreus } \\
\text { Luyben }\end{array}$ & - & 235 & - & 235 \\
\hline $\begin{array}{l}\text { Chien } \\
\text { Hrones } \\
\text { Control }\end{array}$ & - & 98 & - & 98 \\
\hline
\end{tabular}

The Comparison of different PID Controllers ITAE, IAE, ISE, MSE performance index are given below

Table . 4. Error Response Criteria:

\begin{tabular}{|l|l|l|l|l|}
\hline $\begin{array}{l}\text { Tuning } \\
\text { Methods }\end{array}$ & ISE & IAE & ITAE & MSE \\
\hline $\begin{array}{l}\text { Ziegler } \\
\text { Nichol's }\end{array}$ & 63.8401 & 1.4727 & 1.1395 & 0.0044 \\
\hline Tyreus Luyben & 0.29999 & 1.0866 & 2.0116 & 0.0413 \\
& & E+005 & E+005 & \\
\hline $\begin{array}{l}\text { Chien Hrones } \\
\text { control }\end{array}$ & 181.576 & 1.8759 & 1.9474 & 0.0051 \\
\hline
\end{tabular}

\section{CONCLUSION}

The model is characterized and control system for temperature process is analyzed using MATLAB platform. Proportional band, Derivative time and Integral time are fed to PID controller. Output is recorded and the results of various tuning methods depict that Chien-Hrones-Reswick (CHR) tuned PID controller is better than other PID tuning techniques compared. The simulated response for the model corroborated shows the effectiveness of CHR PID controller in terms of time domain specification. The performance index of CHR method PID controller is also better than other PID controllers compared from the real time responses; the CHR method PID controller is suitable for this temperature process.

\section{REFERENCES}

[1] Mohammad Shahrokhi and AlirezaZomorrodi, (2012) Comparison of PID Controller Tuning Methods

[2] Astrom K, J, T. Hagllund, (1994), PID controller Theory, Design and Tuning, 2ndedition, Instrument Society of America

[3] Chen C.L., (1989), a Simple Method for Online Identification and Controller Tuning

[4] Coughanowr D.R. (1991), Process System Analysis and Control,2ndedition McGrawHill

[5] Erickson K.T., J.L. Hedrick, (1999), Plant wide Process Control John Wiley \& Sons

[6] Hang C.C., J.K. Astrom, W.K. Ho, (1991) Refine-ments of Ziegler Nichols Tuning formulaIEE Proceedings

[7] Krishnaswamy P.R., B.E Mary Chan., and G.P, Rangaish; (1987) Closed- Loop Tuning of Control Systems, Chem. Eng.Sci.42, 2173

[8] Luyben W.L, M.L. Luyben; (1997) Essentials of Process Control, McGraw-Hill

[9] Marlin T.E. ;(2000) Process Control, $2^{\text {nd }}$ edition,,$M c$ graw -Hill

[10] Morari M., E. Zafirion; (1989) Robust Process Control, Prentice-Hall, EnglewoodCliffs, $N J$

[11] Ogata K.; (1997) Modern Control Engineering, 3rd edition, Prentice Hall

[12] Seborg, D.E., T.F. Edgar, D.A.Mellichamp; (1989) Process Dynamics and Control, John Wiley \& sons

[13] Smith, C.A., A.B. Copripio; (1985) Principlesand Practice of Automatic Process Control, John Wiley \& Sons Stephanopolous, G.; (1984) Chemical Process Control, Prentice-Hall

[14] Yuwata, M, D.E. Seborg; (1982) A new Method for Online Controller Tuning

[15] K.Mohamed Hussain, R.AllwynRajendraZepherin, M.Shanha Kumar, Comparison of PID controller tuning methods for FOPTD system.

[16] A.R. Laware, V.S. Bandal and D.B. Talange,(2013), Real Time Temperature Control System Using PID controller and Supervisory Control and Data Acquisition System (SCADA), International Journal of Application or Innovation in Engineering \&Management(IJAIEM),

[17] S.M. Giriraj Kumar, R. Ravishankar, T.K. Radha Krishnan, V. Dharmalingam and N. Anantharaman,(2008), Particle Swarm Optimization Technique Based Design of PI Controller for a Real time Non- Linear Process, Instrumentation Science and Technology. 